\title{
Agencias de noticias, su constante reinvención como estrategia para enfrentar la competencia
}

\author{
María Victoria GonZÁlez ClaVERo \\ Universidad Central Marta Abreu de Las Villas (Cuba) \\ mariag@uclv.edu.cu
}

Aceptado: 5 de mayo de 2015

Aceptado: 4 de noviembre de 2015

\begin{abstract}
Resumen
Las agencias de noticias compiten por afianzarse como proveedoras de información y medios de comunicación de masas. Amparadas por una infraestructura tecnológica de primer nivel, Associated Press, Reuters, Agence France Press y EFE constituyen referentes del sistema mediático global debido a las revolucionarias transformaciones que introducen en sus rutinas productivas, cultura profesional, géneros y estilos periodísticos; además por sus novedosas ofertas de productos y servicios. El presente artículo se centra también en las estrategias de las agencias para acercarse más a sus públicos, a partir de los convenios que establecen y del tratamiento de temáticas muy específicas. Finalmente se proponen algunas soluciones que contribuirían a la futura pervivencia de estas entidades.

Palabras clave: periodismo, agencias de noticias, transformaciones tecnológicas, competencia, soluciones estratégicas.
\end{abstract}

\section{News agencies, their constant reinvention as a strategy to face competition}

\begin{abstract}
News agencies compete for a foothold as providers of information and mass media. Covered by a technological class infrastructure, Associated Press, Reuters, Agence France-Presse (AFP) and EFE are leaders of the global media system because they introduce revolutionary changes in their production routines, professional culture, journalistic genres and styles; also for its innovative product offerings and services. This article also focuses on the strategies of the agencies to get closer to their audiences, from the agreements established and the treatment of very specific themes. Some solutions that contribute to the future survival of these entities are also proposed.
\end{abstract}

Keywords: journalism, news agencies, technological changes, competition, strategic solutions.

\section{Referencia normalizada}

GONZÁLEZ CLAVERO, María Victoria (2016): “Agencias de noticias, su constante reinvención como estrategia para enfrentar la competencia". Estudios sobre el Mensaje Periodístico. Vol. 22, Núm. 1 (enerojunio), págs.: 329-341. Madrid, Ediciones Complutense.

Sumario: 1. Introducción. 2. Fuentes y metodología. 3. Soluciones estratégicas al amparo de las tecnologías. 4. Géneros y estilos ante la transformación tecnológica. 5. En contacto con el público. 6. Conclusiones. 7. Referencias bibliográficas.

\section{Introducción}

Las agencias de noticias consolidan su funcionalidad, aun cuando las posibilidades de difundir primicias se han estrechado producto del aumento progresivo de la competencia. Hoy, la profusión de contenidos generados por múltiples emisores y la constante mutabilidad de las tecnologías acentúan el planteamiento de Gans (1979, citado en Wolf, 1987) acerca de que los mass media compiten por inventar nuevos espacios y hacer exclusivas sobre los detalles.

Actualmente las agencias compiten para preservar su rol de proveedoras, debido a que suministran dos tercios de la información que se publica en todo el mundo (Fer- 
nández, 2010, citado en La información.com, 2010). Estas entidades, que al constituir fuentes primarias y gatekeepers del sistema de medios, han contribuido tradicionalmente a la configuración de las agendas, hoy también se afianzan como intermediarias entre el hecho que se genera y los grandes públicos a través de Internet.

Como el resto de los medios de comunicación, a fines de la década del '90 las agencias no quedaron exentas de cuestionamientos acerca de su pervivencia. Paulatinamente las publicaciones científicas más recientes muestran mayor optimismo, entre ellas las de Artero y Moraes (2008), González, et al. (2008), González y Arcia (2014). Según un artículo publicado por el diario The Economist (2009), debido a que las agencias proporcionan una cobertura mayor, son más propensas a sobrevivir a largo plazo que aquellos periódicos que afrontan las consecuencias de la crisis y han tenido que realizar recortes de personal que afectan la cobertura a sucesos internacionales. No obstante, las agencias tampoco han estado ajenas a la realización de despidos, ocasionados por la situación económica ${ }^{1}$.

En la sección "Los compromisos de AFP", que aparece en la web de la agencia en su versión en español, se declara: “[...] sí, las agencias son necesarias. Más que nunca, sin duda ¿Quién aparte de una agencia puede cubrir 150 países, durante las 24 horas del día? ¿Y quién, entre la multitud de fuentes contradictorias, puede garantizar mejor que una agencia la fiabilidad de una información? [...] El oficio del periodista de agencia evoluciona, se reinventa." (AFP, 2014: s/p).

El presente artículo se centra en el aprovechamiento de los recursos tecnológicos por parte de las agencias y en consecuencia las modificaciones que se producen dentro de la labor periodística. El análisis parte de Associated Press (AP), Reuters, Agence France Press (AFP) -líderes en el sistema mediático global-y EFE "primera agencia de noticias en español y la cuarta del mundo" (EFE, 2014: s/p). A dichas empresas se han dedicado la mayoría de las investigaciones relacionadas con este tipo de medio, el menos estudiado y reconocido dentro de áreas del Periodismo y la Comunicación. Además se reconoce que la principal tendencia de las agencias de noticias en la contemporaneidad es: mantenerse vigentes ${ }^{2}$.

\section{Fuentes y metodología}

Se realizó una revisión bibliográfica de los principales autores dedicados a la investigación de las agencias de noticias, tanto en idioma inglés como en español, entre los que destacan Chris Paterson, Ignacio Muro Benayas y María de los Ángeles González Borges; así como de documentos, en el caso de los informes del Reuters Institute; sitios webs relacionados con los congresos mundiales de agencias de noticias, y de medios de comunicación que publican informaciones relacionadas con las agencias.

1 En 2012, El País daba a conocer el despido de más de 270 trabajadores de la agencia EFE, mediante una información de Rosario G. Gómez. Mientras que en 2013, este mismo diario difundía que Thompson Reuters ampliaría hasta 4500 de los despidos para final de 2014, según una nota de Sandro Pozzi.

2 Durante el III Congreso Mundial de Agencias de Noticias, efectuado en Argentina, en 2010, el primer panel de sesiones analizó el tema "La principal tendencia de las agencias de noticias: mantenerse vigente." 
También se analizaron periódicamente las webs de AP, Reuters, AFP y EFE, desde 2013 hasta el primer trimestre de 2015, lo que proporcionó información acerca de las peculiaridades de estas entidades, tanto de manera institucional como de su producción periodística, en cuanto a estilos, géneros y temas. Todo ello posibilitó arribar a inferencias, confirmación de formulaciones teóricas, generalizaciones y conclusiones con el propósito de caracterizar algunas de las soluciones estratégicas emprendidas por las agencias de noticias para enfrentar la competencia y mantenerse vigentes.

\section{Soluciones estratégicas al amparo de las tecnologías}

Lo que el cambio tecnológico proporciona favorablemente, es asimilado por las agencias para dinamizar sus coberturas y prestigiar la imagen que de sí mismas proyectan a sus seguidores. De ahí estas empresas periodísticas realcen su adaptabilidad ante las transformaciones tecnológicas; en una sección de la web de Ap, AP's History, puede leerse: "One reason for AP's longevity has been its ability to adapt quickly to new technologies" (AP, 2014: s/p), mientras que en su Presentación EFE reafirma que "camina con fuerza hacia el futuro y afronta el presente digital preparada para los grandes retos" (EFE, 2014: s/p).

Internet viabilizó el contacto entre los receptores y las agencias, las cuales han ganado mayor reconocimiento social al exponer presentación, caracterización, evolución histórica, premios, valores noticia y alcance a través de textos, imágenes y videos promocionales. Estratégicamente se exteriorizan como opción inmejorable por los recursos tecnológicos y humanos que dedican a la elaboración de sus principales servicios: texto, fotografía, infografía, audio, video, documentación y multimedia; también por principios de trabajo entre los que declaran: rapidez, veracidad, actualidad, exactitud, pluralismo, profundidad e imparcialidad. Ello es consecuencia de su otrora desempeño, prácticamente desconocido, y que ahora compensan con la auto publicidad de sus mejores servicios y técnicas.

Las transformaciones tecnológicas se han incorporado a las agencias como nueva área temática, debido a que el periodismo de innovación es difundido de manera creciente por los medios en la contemporaneidad (Peña y Lazkano, 2013). En tal sentido las agencias resultan beneficiadas porque: 1) tratan las innovaciones tecnológicas como tema de actualidad, novedad; 2) se convierten a sí mismas en noticia, cuando implementan o lanzan nuevos productos tecnológicos ${ }^{3}$ y 3 ) son convertidas en noticia por otros medios de gran reconocimiento, cuando implementan o lanzan nuevos productos tecnológicos ${ }^{4}$.

3 Muestra de ello es que a inicios de 2015, EFE publicaba una nota sobre la oferta de una nueva aplicación para celulares: EFE digital. Además, el 31 de marzo de 2015 AFP dio a conocer AFP Tweetfoot, una solución B2B para seguir el fútbol europeo con Twiter.

4 Un ejemplo de ello lo constituye el periódico británico The Guardian, que publicó a inicios de 2015 las informaciones tituladas Associated Press offers simultaneous live video feeds to news websites, de Roy Greenslade y Reuters launches 'Netflix for news' app, de Dugald Baird; la primera relacionada con la ampliación de servicios de video por parte de Associated Press, con la finalidad de que sus clientes puedan transmitir más de un evento en vivo a la vez, y la segunda referida al lanzamiento de una aplicación de Reuters TV para iphone. 
Con el desarrollo de las tecnologías y su utilización por las agencias, también se aceleran los flujos de producción. Las agencias, a su vez, ofrecen servicios adicionales como elaboración de software, que comercializan con otros medios de comunicación, editores, compañías, entre otros. Tal es el caso de AP, que frecuentemente es noticia por ofrecer estos valores. En 2014, el diario El País, reflejó el incipiente uso de robots por parte de la agencia norteamericana con el fin de elaborar noticias automáticamente (Pereda, 2014); aunque este tema despierta cuestionamientos y polémica que no serán analizados aquí.

Si como explica Jiménez Soler (citado en Peña y Lazcano, 2003) la difusión de innovaciones ha transitado de un modelo reactivo a uno proactivo, que pretende movilizar a los potenciales adoptantes aunque estos no hayan mostrado la necesidad de cambio, entonces resulta muy poco probable que alguna de las grandes agencias divulgue los progresos tecnológicos de sus homólogas -lo cual se verifica en la prácticaporque esa falta de reconocimiento también es parte de su estrategia competitiva.

Hoy, muchas de las innovaciones de AP, Reuters, AFP y EFE están relacionadas con el acceso a sus contenidos desde dispositivos móviles como smartphones, tablets, etc. De estas agencias son las dos primeras las que han logrado mayor implicación en el desarrollo de propuestas para la web móvil (Pere, et al., 2013). Y ese creciente interés se debe a la práctica cada vez más habitual y significativa de empleo de los dispositivos móviles por parte de los usuarios para mantenerse informados. ¿Pero cómo quiere el público recibir las noticias a través de las nuevas plataformas? Sin duda, entre los distintos servicios que generan las agencias debe existir correlación con las necesidades, hábitos de consumo y demás peculiaridades de los receptores, de manera que éstos se sientan atraídos y puedan emplear esos recursos como clientes.

Por ejemplo, una nota publicada por The Guardian, respecto al lanzamiento de una aplicación de Reuters para TV iphone ${ }^{5}$, especifica que se trata de un servicio destinado preferentemente a los consumidores con edades entre 30 y 40 años que valoran la auténtica narración en video y están demasiado ocupados para ver las noticias en la televisión tradicional. Congruentemente, un estudio de Gartner (2011, citado en E1 País.com, 2011) acerca de la lectura en papel y la lectura en pantallas constató que las generaciones de menos de 40 años prefieren la pantalla y que el hombre es más proclive que la mujer al texto digitalizado. Es que como asevera Maciá (1997), la aplicación de nuevas tecnologías a los medios de comunicación, provoca la fragmentación de los receptores y que los públicos se vuelvan más diversos y especializados.

Los destinatarios actuales tienden a una marcada preferencia por la imagen, que ha logrado desplazar al texto. Una relectura del ejemplo citado evidencia que la propuesta de Reuters es de tipo audiovisual. Hoy la generalidad de los productos comunicativos que emiten las agencias en sus webs contienen imágenes, cualesquiera que sean sus variantes: fotografías (independientes y en galerías, estas últimas también denominadas diaporamas y slideshows), gráficos, infografías, videos y videografías ${ }^{6}$.

5 Remitirse a la referencia anterior.

${ }^{6}$ AFP declara que su videografía integra textos, imágenes, fotos y la creación de entornos 3D con un comentario en audio y un script separado para una comprensión en profundidad de las informaciones más complejas. 
La presentación de imágenes, de conjunto con breves informaciones textuales, alcanza además un notable protagonismo en las redes sociales, que las agencias utilizan como extensión de sus sitios y de su presencia en Internet, porque ello les proporciona: 1) reforzar su influencia y el valor de su marca institucional, 2) seguimiento de los públicos y 3) recopilación de noticias, a partir del acceso a fuentes. Eric Carvin, editor de AP, destaca la necesidad del uso de la web social por parte de su agencia, desde el punto de vista competitivo: "We simply needed to start using social to be competitive-indeed, to stay ahead of the competition, as I fell we've established some of the industry's strongest procedures and standard in the area of digital newsgathering" (Carvin, 2012, citado en Griessner, 2012: 16-17).

Un artículo de Marlowe Hood (2015), periodista de AFP encargado del proyecto TweetApp, subraya la utilidad de Twitter para el monitoreo de eventos, encuentro de fuentes, construcción de redes y la presentación de la producción propia de la AFP. Según la encuesta YouGov, aplicada por el Reuters Institute (2014), Facebook constituye la más importante red de noticias a nivel mundial.

En definitiva, que las transformaciones tecnológicas constituyen indispensables aliadas de las grandes agencias informativas, que "crecen simultáneamente en credibilidad y notoriedad hasta ser reconocidas como los medios con más influencia global" (Muro, 2011: s/p). Al amparo de las tecnologías, AP, Reuters, AFP y EFE han emprendido soluciones que implican replanteamiento de las capacidades de sus profesionales respecto a gestión de la información, desempeño polivalente, elaboración de productos multimedia, así como la adopción de diversos géneros y estilos periodísticos.

\section{Géneros y estilos ante la transformación tecnológica}

El estilo predominante en las agencias de prensa, desde sus comienzos hasta la actualidad, es el informativo. La adaptación de los contenidos a los formatos multimedia y su presencia en nuevas plataformas determinan que las noticias de mayor actualidad o breaking news, posean más altos niveles de difusión respecto a otros géneros y estilos.

En el caso de las agencias analizadas, las informaciones que se presentan en las webs responden a diferentes áreas temáticas y proceden de disímiles zonas geográficas. Por lo general solo se colocan en portada de los sitios el titular (AFP), el titular y el lead (Reuters y EFE) o una estructura mixta de titulares solos y otros titulares acompañados de los leads (Reuters y EFE). La mayoría de las informaciones es ilustrada con una imagen, con mayor predominio de la fotografía y el video. Los titulares constituyen hipertextos organizativos y una vez que se accede a las páginas interiores de cualquiera de estos sitios, la presencia hipertextos informativos resulta muy escasa.

La portada oficial de ap.org muestra una amplia imagen fotográfica que varía en dependencia de su actualización, facilita considerable información sobre la agencia, así como sus nuevos servicios, pero no propicia el acceso de los usuarios comunes a sus productos comunicativos. Desde una de sus versiones ${ }^{7}$, que incluye informaciones en es-

${ }^{7} \mathrm{http} / /$ /hosted.ap.org/dynamic/fronts/NOTICIAS_GENERALES?SITE=AP\&SECTION=HOME 
pañol, consta de los titulares de las noticias acompañados de sus leads, sección Último momento. También dedica un apartado a textos encausados al periodismo de servicio. Mientras que en inglés incluye las secciones Big story, Top news, Special coverage, Archive y Video, todas con carácter generalista y con predominio del estilo noticioso.

El sitio web de AFP solo ofrece contadas informaciones ya sea mediante textos o imágenes. Pero ha de resaltarse que como es inusual para el resto de los medios, consta de los blogs Making-of (versión en francés), Correspondent (versión en inglés) y Focus (versión en español) en los que se difunde información tras bastidores, cómo se hace la noticia. Desde un estilo cercano a la crónica, se recuentan las vivencias del personal periodístico en escenarios muy singulares, donde el emisor es partícipe del propio relato. Están presentes en esos textos pormenorizadas narraciones y descripciones de lugares, personas y hasta las impresiones propias de quien escribe, pues AFP y AP son entre las agencias que aquí se analizan, la que más refuerzan su imagen a través de la insistente difusión de su historia, valores y funcionamiento, lo que supone un valor agregado. Corresponde esta estrategia a un planteamiento de Emmanuel Hoog, Presidente de AFP, en la reunión de la Alianza Europea de Agencias de Prensa (EANA), efectuada en 2012: "We need to be able to provide our audience with contents but also with information about ourselves and our way to produce news content" (Hoog, 2012: s/p).

EFE también concede gran relevancia a la noticia, que prevalece en portada; y en menor medida presenta otros géneros como la crónica, el reportaje y la entrevista. De ellos tres solo figuran en portada la identificación del género, el titular y el primer párrafo, acompañados de una imagen. Para los usuarios comunes es posible acceder a la lectura íntegra de las noticias, las crónicas y entrevistas, pero no de los reportajes. En la portada varios links remiten a las webs temáticas de EFE (EFE: Tur, EFE: Estilo, EFE: Salud, EFE: Emprende, entre otras) con marcado carácter de periodismo de servicio y cuyos productos comunicativos están a disposición de los usuarios comunes. Estas Webs temáticas contienen textos, imágenes y posibilitan la revisión de vídeoblogs (sobre todo en el caso de EFE: Salud). Mientras la plataforma EFE: Doc, difunde análisis, trabajos a fondo, cronologías y biografías, que para su completo acceso exigen determinados condicionamientos.

En cambio Reuters provee noticias de corte generalista en su sitio web, aunque es una agencia especializada. Consta de los apartados Analysis \& Opinion y Breakingviews, destinados al ejercicio de la interpretación y la opinión, lo que la distingue del resto de las agencias aquí analizadas. Para salvaguardar su status y la responsabilidad que puede contraer la publicación de materiales periodísticos que impliquen mayor compromiso, hace acompañar el nombre del autor de aclaraciones del tipo: "Any opinions expressed here are those of the author and not necessarily of Reuters", o "Any opinions expressed here are the author's own".

Si bien la prevalencia del estilo informativo es incuestionable, las agencias no desestiman géneros ni maneras de comunicar. Como puede verificarse el periodismo de agencia en la actualidad recurre a los estilos ideológico, informativo, interpretativo y de servicio; a diferencia de varias décadas atrás, cuando se centraban en lo puramente informativo. 
Cabe aclarar que no todas las agencias aquí analizadas transmiten estos estilos desde sus sitios web, pero sí los producen para su clientela. He ahí la revalorización del periodista como experto que analiza, interpreta y explica lo que ocurre (Tuñez, et al., 2010). Pese a que el logro de una mayor profundidad y explicación de los hechos al lector constituye un propósito, todavía las agencias quedan en desventaja respecto a otros medios de comunicación en lo que respecta al análisis y la opinión.

Según el ranking de Alexa, que comprende a los sitios webs de medios informativos con mayor impacto, en la categoría news/breaking news, la agencia Bloomberg ocupa el lugar número dos y Reuters.co.uk se ubica en la posición 41. Mientras que en la opción news/services Reuters.com aparece en el primer puesto, AP.org en el tercero y AFP.com en el séptimo. Sin embargo, la clasificación news/analysis and opinion, no incluye a ninguna de las cuatro grandes.

La concepción de géneros y estilos representa un constante reto porque plantea la búsqueda de renovadas maneras de comunicar, y estas entidades, desde su surgimiento y luego durante décadas estuvieron muy ceñidas a lo puramente informativo. Mas la crisis del modelo económico de la prensa escrita (principal cliente de las agencias), la fuerza de la información visual y la innegable presión que ejerce la competencia, han obligado a estas empresas a ampliar y diversificar su producción porque ahora está destinada a nuevos consumidores.

\section{En contacto con el público}

De acuerdo con Ignacio Muro (2011) la antigua clasificación entre medios mayoristas y minoristas se desdibuja actualmente ante los usuarios. Si antes los destinatarios de las agencias eran los medios de comunicación, hoy se suman gobiernos, partidos, bancos, empresas, organizaciones, administraciones, agencias publicitarias, usuarios comunes (estos últimos con acceso más o menos limitados a los contendidos). Las necesidades específicas de los clientes se satisfacen bajo demanda, encargos a la carta entre los que pueden aflorar lo mismo la realización de coberturas especiales, que de comunicados, asistencias técnicas, paquetes temáticos, videos institucionales. Los archivos gráficos, de texto y audiovisuales sirven como material de consulta a los suscriptores y cuentan con amplios volúmenes de información en distintos idiomas que se engrosan con lo más trascendente del quehacer cotidiano.

Este contacto más inmediato entre agencias-público se produce en un contexto en el que la recepción es eminentemente activa. Los receptores hoy no solo pueden elegir a través de qué medio o medios informarse, sino contrastar, interactuar y generar contenidos. Y esta posibilidad final también es aprovechada por las agencias, amén de que constan de amplias redes de corresponsalías y que las colaboraciones requieren de una meticulosa comprobación.

Con el propósito de satisfacer las crecientes necesidades informativas de sus clientes, las agencias además establecen convenios con entidades homólogas cuyo alcance y perfil editorial varían. A juicio de Castro (1995) la colaboración entre agencias no es nueva, propicia que las agencias de menor alcance constituyan un interesante cliente para las redes transnacionales y que supongan a veces el conducto obligado de llegada a los periódicos. El intercambio de servicios informativos entre agencias con idiomas 
distintos facilita un acceso más inmediato a los acontecimientos. Es así como las partes se convierten en fuentes mutuas para consolidarse como referentes con toda la instantaneidad posible.

Una de las definiciones más recientes de agencia de noticias, elaborada con motivo del Cuarto Congreso Mundial de Agencias de Noticias, resalta el establecimiento de estos acuerdos:

"A news agency is an organization that produces and distributes its own, original news, including a general news service, and has agreements with the media and other subscribers, and is relevant in its market. A news agency, which can have either a national or international focus, can include among its products contents from other news agencies, provided the relevant parties have an agreement to cover this use" (NAWC, 2013: s/p).

El intercambio puede resultar muy diverso si se toma en cuenta que las agendas de AP, Reuters, AFP y EFE se conforman fundamentalmente con tópicos como economía, política, cultura, deportes, ciencia, tecnología, salud, ecología y conflictos (aunque para la especializada Reuters, son primordiales los acontecimientos de la esfera económica).

La coexistencia con los hábitos de consumo de los usuarios en Internet -en los que la búsqueda de información en medios de comunicación no encabeza los favoritos- motiva la capacidad de entretener desde las webs de las agencias (sobre todo en el caso de las generalistas) a partir de la inclusión de temáticas como ocio, moda, estilos de vida, personajes públicos y hasta sugerencias de destinos turísticos o eventos sociales.

AFP, por ejemplo, estableció convenios con relaxnews -agencia especializada en ocio- para lanzar en 2009 el primer hilo mundial de información acerca de bienestar, hogar, divertimento y turismo. Reuters y AP constan de secciones de entretenimiento y dan cobertura a espectáculos, famosos y moda. Mientras EFE difunde las temáticas del perfil de ocio esencialmente en su apartado Gente, y las Webs temáticas EFE: Tur y EFE: Estilo.

El tratamiento de las non-burdening stories ${ }^{8},-$ noticias ligeras que no agotan a los receptores- goza ya de una presencia habitual en las agencias de prensa, que apelan a estas temáticas como poderoso recurso de atracción de sus públicos. Lo mismo sucede con la cobertura y seguimiento noticioso de las tecnologías, sus transformaciones y aplicaciones. De modo que los valores noticia novedad y jerarquía de personajes implicados, ${ }^{9}$ evidencian un notable realce en la producción periodística actual de estas entidades.

Asimismo la nueva tendencia que comienza a gestarse en los medios de comunicación, consistente en la difusión de noticias raras, insólitas y hasta divertidas, es aprovechada por las agencias. Tal es el caso de Oddly Enough, sección de Reuters en su sitio web, que difunde noticias de esa naturaleza, ya que las: "weird news proving more/as popular than entertainment news" (Newman, 2014:8).

El empeño por mantener la prevalencia, y por qué no el favoritismo de los destinatarios, pudiera constatarse, entre otros indicadores, a partir de las visitas de usuarios a las webs de las agencias. En correspondencia con este criterio, según el ranking de

${ }^{8}$ Esta clasificación se aviene al criterio de Gans (1979, citado en Wolf, 1987).

${ }^{9}$ Esta clasificación de valores noticia corresponde al criterio de Stella Martini (2000). 
4 International Media \& Newspapers, en 2014 Reuters ocupaba el segundo lugar precedida por Xinhua, AP se situaba en el puesto número cuatro, AFP en el 10 y EFE en la posición número 30 .

Mientras que en el Top 500 de sitios en la Web, elaborado por Alexa, Xinhuanet.com se encuentra en el lugar 125, y Reuters.com en el 373. Algunos factores influyen decisivamente como el idioma y la disponibilidad de contenidos de libre acceso, pues como explica Chris Paterson:

"AP [...] only provide links at its own website to its content through the websites of member newspapers. Reuters, [...] essentially gone into competition with its subscribers and become online news services marketing directly to the consumer and through its branded stories provided by news aggregators" (Paterson, 2006: s/p).

Al respecto Juan Pablo Artero y Renata Moraes, coinciden en que Reuters y AFP mantienen distintos criterios acerca de la presentación de su producción en Internet y la gratuidad de sus ofertas: "Mientras la primera cree que cuanto más conocida sea por el público general, más valor agregado se le supone, la francesa defiende la exclusividad de sus contenidos" (Artero y Moraes, 2008: s/p). Además, Reuters deviene la menos reservada en cuanto a la presentación de géneros interpretativos y de opinión, a diferencia de las otras tres que privilegian lo noticioso en sus websites.

A las agencias de noticias, les queda todavía pendiente en sus agendas un mayor acercamiento a lo local como respuesta a los intereses de los receptores. Algunos de los reclamos más comunes a estas entidades se centran la necesidad de un periodismo más dirigido a los procesos que a los sucesos, en el que primen más análisis y explicaciones y donde haya menos show; deben dar voz a los protagonistas no tradicionales, a las fuentes alternativas y a temas como el desarrollo humano; precisan del logro de una mayor neutralidad informativa (Fasano, 2010, citado en Urquhart, 2010). Muro (2011) enfatiza que las agencias deberían aprovechar más sus redes de corresponsales para garantizar la fiabilidad de las contribuciones en cada materia, y actualizar su rol de gatekeepers en función del interés general.

Otras propuestas que contribuirían a la calidad e integralidad de los servicios radican en la ampliación y diversificación de las modalidades de periodismo: especializado, investigativo y de precisión; también la presentación con cierta asiduidad de algunas de sus producciones mediante fórmulas más recientes como la narrativa transmediática, caracterizada por ahondar en los acontecimientos a partir de su contextualización, el empleo de documentaciones, la presencia de diferentes puntos de vista y de las subhistorias. Según Ilara (2014) la narrativa transmediática permite la revalorización del periodismo literario y el periodismo de datos, además de la comunicación más profunda con el lector.

Se trata, esencialmente, de que la cantidad y la inmediatez no menoscaben la calidad de las producciones periodísticas de las agencias, ahora cuando han ampliado sus canales de acceso y han entrado en contacto con un público más heterogéneo. Hoy constan de recursos tecnológicos y personal capacitado suficientes, que les permite asumir el reto de una reinvención constante para enfrentar la competencia y mantenerse vigentes. 


\section{Conclusiones}

Las agencias de noticias AP, Reuters, AFP y EFE constituyen referentes a escala global, tanto por su producción periodística, como por su capacidad de adaptación a los escenarios actuales. Entre sus potencialidades destacan:

- Dualidad de funciones: proveedoras de información para el sistema de medios y el resto de sus clientes al mantener su condición de fuentes confiables, mientras que para los usuarios comunes se instituyen como medios de comunicación de masas.

- Infraestructura tecnológica de primer nivel.

- Amplia red de periodistas y corresponsales que posibilitan la cobertura de acontecimientos en disímiles áreas geográficas.

- Elaboración de productos multimedia.

- Diversificación en el empleo de estilos: informativo, interpretativo, opinativo, de servicio.

- Diversificación en el empleo de géneros: nota informativa, crónica, entrevista, reportaje, análisis, comentario, artículo.

- Amplio tratamiento de temas: incorporan el periodismo de innovación, y para atraer a los usuarios recurren a los tópicos: ocio, entretenimiento, informaciones raras o insólitas y hasta de diversión.

- Establecimiento de acuerdos que les permiten ampliar su caudal informativo.

Sin duda, la reinvención y generación constante de nuevas propuestas devienen el más poderoso ardid de las agencias noticiosas para responder a las exigencias que le plantea el contexto; aunque también han sido criticadas por su previsibilidad y homogenización, demostradas en el tratamiento de algunas de sus producciones. Les queda irresuelto un mayor acercamiento y explotación de las modalidades: especialización, investigación, precisión y narrativa transmediática para competir con calidad en esta época, donde el periodismo puede o no poner en juego su propia pervivencia.

\section{Referencias bibliográficas}

AFP (2014): "Valores y compromisos/ Los compromisos de AFP" en AFP: http://www .afp.com/es/agencia/valores-compromisos [Consulta: 12 de agosto de 2014]

ALEXA (2015): Top sites in: All Categories > News> Analysis and opinion, en Alexa: http://www.alexa.com/topsites/category/Top/News/Analysis_and_Opinion [Consulta: 9 de marzo de 2015]

ALEXA (2015): Top sites in: All Categories> News> Breaking News, en Alexa: http://www.alexa.com/topsites/category/Top/News/Breaking_News [Consulta: 9 de marzo de 2015]

ALEXA (2015): “Top 500 sites on the Web” en Alexa: http://www.alexa.com/topsites [Consulta: 9 de marzo de 2015]

ANB (2010): "Debates sobre comunicación en el Congreso Mundial de Agencias", en $A N B$ : http://www.anbariloche.com.ar/noticia/16860-debates-sobre-comunicacionen-el-congreso-mundial-de-agencias [Consulta: 4 de junio de 2014] 
AP (2014): “AP's History” en $A P$ : http://www.ap.org/company/history/ap-history [Consulta: 12 de agosto de 2014]

ARTERO, Juan Pablo y MORAES Renata (2008). "Opciones estratégicas de las agencias de noticias europeas: Reuters, France Press y EFE" en Comunicación y Sociedad: http://www.unav.es/fcom/communication-society/descarga_doc.php ?art_id=37. [Consulta: 17 de junio de 2013]

BAIRD, Dugald (2015): "Reuters lauches 'Netflix for news' app" en The Guardian, 5 de febrero: http://www.theguardian.com/media/2015/feb/05/reuters-tv-app-netflix-for-news-iphone [Consulta: 9 de marzo de 2015]

CASTRO SAVOIE, José Ángel (1995): Las agencias transnacionales de prensa al final del siglo XX. Impacto del nuevo orden mundial de la información y de la comunicación en los objetivos informativos de las grandes redes periodísticas (19731993). Tesis doctoral. Universidad Complutense de Madrid.

EFE (2014): "Presentación" en EFE: http://www.efe.com/efe/queesefe/presentacion/espana/ [Consulta: 12 de agosto de 2014]

EL PAÍS (2011): "Se iguala el tiempo de lectura en pantalla y papel. Gartner asegura que la sustitución de los medios impresos por los digitales se ha exagerado" en $E l$ Pais, 10 de mayo: http://tecnologia.elpais.com/tecnologia/2011/05/10/actualidad/1305018065_850215.html [Consulta: 9 de octubre de 2014]

GÓMEZ, Rosario G. (2012): “La agencia EFE y el diario 'El Mundo’ planean despedir a 400 trabajadores", en El Pais, 6 de junio: http://sociedad.elpais.com/sociedad/2012/06/06/actualidad/1338997840_680142.html_[Consulta: 4 de junio de 2014]

GONZÁLEZ BORGES, María de los Ángeles y ARCIA SOCORRO, Glenda (2014): "Siguiendo la ruta de las agencias en el siglo XXI: mediaciones y producción periodística" en Latina de Comunicación Social: http://www.revistalatinacs.org /14SLCS/2014_actas/136_Gonzalez.pdf [Consulta: 14 de marzo de 2015]

GONZÁLEZ LEMES, Ivet; BRIZUELA BRÍNGUEZ, Luis; y GONZÁLEZ BORGES, María de los Ángeles (2008): "Tocar el fondo a un chasquido de dedos. Aproximaciones a las características del estilo interpretativo en las agencias de noticias": en Estudios sobre el Mensaje Periodístico, vol. 14, pp. 419-433. Madrid, Servicio de Publicaciones de la Universidad Complutense.

GRIESSNER, Christoph (2012): "News agencies and social media: a relationship with a future?" en Reuters Institute Fellowship Paper University of Oxford: http://www.scribd.com/doc/212032489/News-Agencies-and-Social-Media\#scribd [Consulta: 4 de mayo de 2014]

GREENSLADE, Roy (2015): "Associated Press offers simultaneous live video feeds to news websites" en The Guardian, 10 de febrero: http://www.theguardian.com/media/greenslade/2015/feb/10/associated-press-offers-simultaneous-live-video-feeds-to-news-websites [Consulta: 9 de marzo de 2015] 
HOOD, Marlowe (2015): “¿Mejores amigos o amigos-enemigos?”, en AFP.com, 31 de marzo: http://blogs.afp.com/focus/?post/twitter-y-las-agencias-de-noticias\# .VT5Lmi4x6cE [Consulta: 16 abril de 2015]

HOOG, Emmanuel (2012): "News agencies in the digital era. Keynote speech by Emmanuel Hoog, CEO, Agence France-Presse 2012 meeting of the European Alliance of Press Agencies (EANA)" en AFP.com, 10 de mayo: http://www.afp.com/en/node/107135/ [Consulta: 16 abril de 2015]

ILARA HORTAL, Pilar (2014): "Nuevas narrativas en el periodismo actual. El periodismo transmediático". Estudios sobre el Mensaje Periodístico, vol. 20, núm. 1, pp. 147-158. Madrid, Servicio de Publicaciones de la Universidad Complutense.

4 INTERNATIONAL MEDIA \& NEWSPAPERS (2015): “News Agency", en 4 International Media \&Newspapers: http://www.4imn.com/news-agencies/_[Consulta: 16 abril de 2015]

LA INFORMACION.COM (2010): "Integración multimedia e innovación, en el foco de atención de las agencias", en La información.com: http://noticias.lainformacion.com/economia-negocios-y-finanzas/agencias-de-noticias/integracion-multimedia-e-innovacion-en-el-foco-de-atencion-de-las-agencias bsINBUgC0 $\mathrm{pJttbxGa}$ gtD01/ [Consulta: 14 de marzo de 2015]

MACIÁ MERCADÉ, Juan (1997): "La fuerza del periodismo local en la era de la globalización electrónica". Revista Estudios de periodística, vol. V. Número especial dedicado al periodismo local.

MARTINI, Stella (2000): "Periodismo, noticia y noticiabilidad" en Nombre Falso, comunicación y sociología de la cultura: http://www.nombrefalso.com.ar /index.php?pag=96 [Consulta: 22 de marzo de 2008]

MURO BENAYAS, Ignacio (2011): "El papel de las agencias de noticias, una nueva mirada", en Conexiones: https://imuro.wordpress.com/2011/12/25/el-papel-de-lasagencias-de-noticias-una-nueva-mirada/ [Consulta: 28 de abril de 2015]

NAWC, (2013) "Preamble" en NAWC Statutes- IV News Agencies World Congress: http://nawc.com.sa/mobile/index.php/blog-2/nawc-statutes [Consulta: 8 de enero de 2015]

NEWMAN Nic. Y LEVY David A. L. (2014): "Reuters Institute digital news report 2014. Tracking the future of news" en Digital News Report: https://reutersinstitute.politics.ox.ac.uk/sites/default/files/ReutersInstituteDigitalNews Report 2014.pdf [Consulta: 13 de abril de 2015]

PATERSON, Chris (2006): "News agency dominance in international news on the Internet". Papers in International and Global Communication. Centre for International Communications Research: http://ics.leeds.ac.uk/papers/cicr/exhibits/42 /cicrpaterson.pdf_[Consulta: de 23 de enero de 2009]

PEÑA FERNÁNDEZ, Simón y LAZCANO ARRILLAGA, Iñaki (2013): “Innovar en comunicación. Tendencias actuales de investigación" en Latina de Comunica- 
ción Social: http://www.revistalatinacs.org/13SLCS/2013_actas/156_Pena.pdf [Consulta: 17 de septiembre de 2014]

PERE FREIXA J.; RIVAS, Ignasi y CODINA, LLuís (2013): “Comparative Analysis of Mobile web applicattions for the main international news agencies: state of the art and preliminary results": http://www.academia.edu/7389340/Comparative analysis_of_mobile_web_applications_for_the main_international_news_agencies_state_of_the_art_and_preliminary_results [Consulta: 24 de abril de 2015]

PEREDA, Cristina F. (2014): "El periodismo se enfrenta al reto de los robots que elaboran noticias" en El País, 21 de julio: http://sociedad.elpais.com/sociedad/2014/07/11/actualidad/1405101512_992473.html [Consulta: 23 de septiembre de 2014]

POZZI, Sandro (2013): “ThompsonReuters amplía hasta 4500 los despidos" en $E l$ Pais, 29 de octubre: http://economia.elpais.com/economia/2013/10/29/actualidad/1383061766_066873.html [Consulta: de 26 de octubre de 2014]

THE ECONOMIST (2009): "With newspapers in crisis, newswires may learn to live without them", en The Economist, 12 de febrero: http://www.economist.com/node/13109820 [Consulta: 24 de abril de 2015]

TUÑEZ LÓPEZ, Miguel; MARTÍNEZ SOLANA, Yolanda; y ABEJÓN MENDOZA, Paloma (2010): "Nuevos entornos, nuevas demandas, nuevos periodistas" en Estudios sobre el Mensaje Periodístico, vol. 16, pp. 79-94. Madrid, Servicio de Publicaciones de la Universidad Complutense.

URQUHART DE BARROS, Juan Carlos (2010): “Culminó el congreso mundial de agencias de noticias", blog personal: http://reflexionesvetero.blogspot.com /2010/10/culmino-el-congreso-mundial-de-agencias.html [Consulta: 26 de octubre de 2014]

WOLF, Mauro (1987): La investigación de la comunicación de masas. Crítica y perspectivas. Barcelona, Paidós.

Maria Victoria González Clavero es Licenciada en Periodismo en 2008, con Título de Oro. Máster en Ciencias de la Educación en 2012. Profesora de la carrera de Periodismo de la Universidad Central "Marta Abreu" de Las Villas (Santa Clara, Cuba) desde 2008 hasta la actualidad. Sus líneas de investigación son: "Funcionamiento de las rutinas productivas en medios impresos, digitales y agencias de noticias"; y "Desarrollo de la autonomía en el aprendizaje en estudiantes que ingresan a la Educación Superior en el curso regular diurno". Ha participado en eventos nacionales e internacionales y ha publicado artículos en revistas académicas de México, España y Venezuela. 